se ha luchado históricamente por el acceso de la mujer a determinadas tareas o profesiones, puede lucharse ahora por la erradicación de ese tipo de diferencias. El progreso social ha logrado superar la separación por sexos que pudo existir en las labores docentes, o la que a veces ha podido apreciarse en algunos reductos de la actividad artística, científica o literaria. ¿Podrá ocurrir algo similar con el deporte profesional? Más allá del deporte, chabrá todavía en nuestra sociedad parcelas profesionales segregadas que merezcan consideración desde este punto de vista? ¿Qué está ocurriendo en ese sentido a lo largo y ancho del sistema productivo? ¿Qué sucede, por ejemplo, en los estratos más básicos o rutinarios de la producción de bienes o servicios? El libro de Martínez Girón y Arufe Varela, bien complementado por el prólogo de Milagros Calvo Ibarlucea, nos pone sobre aviso.

Joaquín GarCía Murcia Dpto. de Derecho del Trabajo y de la Seguridad Social. UCM

\title{
J. L. Requejo Pagés, El sueño constitucional, Oviedo, KRK, 2016, 274 pp.
}

El profesor Requejo ha construido un muy interesante ensayo sobre la crisis de la estatalidad europea, aún más interesante por la significación y la posición del autor. Lo componen, en forma muy bien articulada, por una parte, una filosofía del Derecho y del Estado kelseniana y hobbesiana escasamente original, lo que no es una crítica, porque precisamente hace mucha falta recordar lo sabido; por otra, una inteligente interpretación del sentido de la institucionalización europeísta, con la tesis medular, estrictamente política y polémica, de que es ya urgente la constitución de la República Federal de Europa (en la que, por cierto, no se nos dice qué haremos con los reyes). Para ello hace falta que el constitucionalismo, como ciencia jurídica y como ideología política, se aplique a la creación y fortalecimiento del nuevo soberano antes de pensar en imponerle límites (pp. 216-220) y, claro está, un impulso político que no se acaba de ver bien de dónde puede surgir. Requejo describe la decadencia de nuestros Estados nacionales como impotencia ordenadora (pp. 191-194), cuyas causas habría que buscar en la obsesión por la limitación del poder (p. 168), en la constante frustración de las posibilidades idealizadas de realización efectiva de la más perfecta libertad e igualdad (pp. 174-177), 
en el abuso del ideal democrático (pp. 177-185), en la incomprensión en anchas capas de población, nueva o no, de las bases de mentalidad que postula y presupone el sistema y, sobre todo, en la inadecuada dimensión a que los Estados han quedado reducidos por la honda mutación de nuestra época globalizadora, que es el leitmotiv de este drama.

El capítulo I teoriza el Derecho como técnica de organización del ejercicio de la fuerza a partir de la consideración del hombre como ser natural. Requejo es un convencido kelseniano, título con el que no estoy muy seguro de que se haya llegado a navegar a favor de la corriente, pero un kelseniano que sabe que Kelsen es prisionero de Hobbes (p. 69). El estado de naturaleza del hombre, la condición humana de cosa que lo es por naturaleza, es la libertad para quien en cada momento sea el más fuerte. La violencia es inherente a la condición humana y, todo lo más, se puede regular razonablemente. La religión es sólo «el delirio de la fantasía», la «trágica maldición de la inteligencia desviada» (p. 37), y la justicia, «un valor, esto es [...] una posición de principio inasequible a la discusión racional» (p. 44). El Derecho no es un instrumento de la justicia, sino tan sólo un mecanismo de seguridad. La certeza sobre el origen previsible de la fuerza cons- tituye «un factor de pacificación de primer orden» (p. 49). Otros fines, cualesquiera que sean, se llamarán justicia, cuya capa recubre siempre el interés parcial dominante, pero no podrán ser objeto de debate racional.

Sobre estas bases sólo cabe «el respeto a la discrepancia o la victoria del más fuerte» (p. 44). En esta alternativa parece fundarse el argumento democrático del relativismo, la extraña alquimia de que una universal degradación axiológica ponga «las condiciones necesarias para la fundamentación racional del Estado a partir de un determinado orden de valores» (p. 45), que es el de la máxima libertad individual compatible con la seguridad de todos.

Requejo reitera la conexión entre formalismo y libertad, adhiriéndose plenamente a la concepción procesal del Derecho. Los principios que mejor pueden configurar el Derecho en orden a la libertad son los típicamente procesales: procedimiento abierto, deliberación, debate, decisión y, muy en particular, reversibilidad de lo decidido. Una visión procesal, formal, devalúa los contenidos y los hace más fácilmente eliminables por sustitución. Para la fluidez en el tránsito «es imprescindible la relativización de todo contenido posible» (p. 47). Se relativizan así todos los valores menos uno, el del pro- 
cedimiento mismo, pero el procedimiento juega «en beneficio de la libertad individual». El problema es, obviamente, aunque la objeción es por lo menos tan antigua como la tesis misma, si es posible construir, y aun simplemente sobrevivir, en arenas movedizas. El movimiento constitucionalista $-\mathrm{y}$ este es el motivo de toda la reflexión de Requejo- está dando, «frente a los términos en los que el poder se manifiesta y se desenvuelve en las sociedades de la posmodernidad», una respuesta insuficiente (p. 48). En este punto aflora una de las muchas reflexiones lúcidas de que, procurando fríamente no pisar las líneas, está lleno este libro, cuando viene a reconocer (p. 49) la constitutiva debilidad de este supuesto de civilización (pero de una civilización que, como decía Jesús Fueyo, es una mutación permanente) al decirnos que «acaso el [concepto de hombre] más operativo y cierto sea el que hace abstracción del individuo y todo lo cifra en la especie».

El resto del capítulo I trata de resumir el significado de la emergencia de la modernidad europea, sobre la distinción entre los que llama paradigmas aristotélico y hobbesiano (pp. 49-70). Requejo, que relativiza hasta el concepto de la dignidad humana (p. 48), es muy consciente de la profunda cesura que nos separa de Oriente. Nosotros hemos cifrado siempre en la libertad individual el único fin legítimo del Estado: «La cultura de Occidente [...] no es más que su consecuencia inevitable» (p. 51).

Con adhesión, también en esto, a las ideas más comunes, mantiene Requejo la primacía de la experiencia griega clásica - ateniense- en la filosofía política. Toda la cultura occidental trae causa de la individualidad del hombre y de su condición de medida de la realidad (p. 51). El humanismo se completa con la divinización cristiana del hombre, que es el principio y la clave de las ideas de dignidad y autonomía individual, cuyo origen cristiano, tan torpemente discutido desde la Ilustración, se cuida de recordar (p. 73) ${ }^{1}$.

A partir del humanismo, «todo se reduce a una cuestión de límites» (p. 52). La preocupación por el límite —que a juicio de Requejo llega a ser obsesión en el constitucionalismo contemporáneo- es ya consustancial al pensamiento político clásico. La comunidad política tiene, en paralelo con la física teleológica de Aristóteles (p. 54), un fin natural que impone límites y es el criterio para juzgar sobre la bondad de las formas políticas (p. 53).

En este punto remite, por todos, al reciente libro de L. SIEDENTOP, Inventing the Individual: The Origins of Western Liberalism, London, Allen Lane, 2014. 
Para Requejo este modelo - que juzga dogmático- empezó a fracasar con la crisis de las ciudadesestado (p. 55), pero pudo perpetuarse gracias al Imperio romano, cuya extensión espacial no alteró su cualidad (p. 57). «[E]1 monopolio de poder ad intra nunca fue contestado [...] El objeto de la discordia era la titularidad» (p. 58). Desde este punto de vista, la caída del Imperio romano no fue aceptada intelectualmente (p. 58) y el mito imperial se reencarnó — dice- en la Iglesia romana, que fue capaz de continuarlo en cuanto depositaria legítima de la autoridad espiritual que - a su juicio- era parte constitutiva del Imperio desde Constantino. La unidad final de la civitas, orientada a la realización de la bumanitas, subsistía en la res publica christiana, ordenada a la salvación de las almas.

Pudo así persistir un solo centro de imputación al que se refería todo poder legítimo: la voluntad de Dios. Ciertamente, había una diferencia muy importante, «una dualidad constitutiva que - según entiende Requejo- no tenía equivalente en la ciudad antigua» (p. 60). Hubo largas luchas por la primacía y muchos intentos teóricos de fundamentar la autonomía de los poderes temporal y espiritual, unificándolos en la voluntad de Dios, con separación de las titularidades en razón de la diversidad de fines natu- rales, pero la dualidad del poder -material, funcional e institucional- era en el fondo una anomalía, porque todo intento de división de un poder absoluto tiende mecánica y fatalmente a resolverse con la imposición excluyente de una de las partes (p. 61), con lo que Requejo desconsidera absolutamente la distinción entre auctoritas y potestas.

Siendo difícil precisar cuál fue el factor determinante de la ruptura -quiebra radical (p. 85)de la unidad del mundo medieval, Requejo se refiere globalmente al «progresivo dinamismo de la sociedad» (p. 63) y a «la revolución intelectual, material y científica del Renacimiento [que] estaba sentando las bases de la sociedad capitalista» (p. 64). Se operó, sobre todo, una alteración profunda en la percepción de la realidad, que puso fin al universo aristotélico de las leyes físicas basadas en el principio del movimiento natural, teleológicamente ordenado. En su lugar, se estableció una cosmovisión basada en el carácter caótico y mecánico del movimiento. Sobre estas premisas, Requejo detecta una obsesión por el cambio (p. 64) y una necesidad de su institucionalización (p. 63).

Así como «[las] fuerzas físicas ya no tenían un fin natural, tampoco el poder podía tenerlo, es más, necesitaba no tenerlo. Para formalizar su poder efectivo, autónomo, no podían los reyes justificarse con 
el viejo recurso al fin natural de la comunidad política, porque ese fin natural implicaba límites, y para dar una respuesta a la necesidad de cambio en el orden social y económico se necesitaba un poder liberado o que pudiera liberarse de aquellos límites. Este nuevo poder no podía reconocer otro que el de su propia fortaleza. «La posibilidad de que la contradicción [...] sea [...] un cambio lícito pasa por la introducción de un criterio de validez que no se confunda con una realidad inamovible, sino [...] susceptible ella misma de cambiar. La reforma $[. .$.$] exigía que la discre-$ pancia con lo establecido [...] se resolviera [...] de acuerdo con [...] la voluntad del poderoso» (p. 65). «Cuando los monarcas nacionales se sintieron lo suficientemente fuertes como para arrogarse como propio un poder que hasta entonces sólo era dependiente y vicario, encontraron en su propia fuerza el argumento decisivo» (p. 65). Radicó éste en que tan sólo ellos podían garantizar la paz. Su poder era legítimo porque garantizaba la paz. La pacificación requería un poder soberano. «[L]os nuevos centros de poder [...] hallaron [un fundamento propio] en su aptitud para el monopolio y ejercicio eficaces de una fuerza irresistible [...] [que] era, en realidad, la circunstancia de la que traía causa su posición de dominio» (p. 63).
El paradigma hobbesiano se basa en una física de fuerzas desordenadamente contradictorias. Las fuerzas individuales o parciales sólo pueden someterse a un orden de paz social mediante la actuación de una fuerza superior a todas ellas, irresistible, capaz de sujetar a todos, individuos y facciones. Esta fuerza en el estado natural de la sociedad no existe. Sólo puede surgir como creación artificial (p. 67).

El capítulo II trata del Estado nacional europeo en sus relaciones internas, comenzando, en la línea de Passerin d'Entreves, por una exposición de las cuestiones generales de legitimación del poder. En toda comunidad humana «alguien [...] somete por la fuerza a la mayoría desde una posición de preeminencia» (p. 77). Unos mandan y otros obedecen. Hay una «diferencia radical, de principio [...] entre quienes demuestran ser más fuertes y quienes, por no serlo tanto, les están efectivamente sometidos» (p. 78). Cuando se ha alcanzado tal posición de preeminencia, lo normal es que se pretenda consolidar y perpetuar (p. 77), para lo que se aplican estrategias de legitimación (p. 77), porque la desnuda expresión de la dominación como pura cuestión de fuerza haría demasiado patente la precariedad de la posición del sujeto dominante (p. 78).

Aunque las relaciones de poder expresan en la realidad social un 
equilibrio circunstancial de fuerzas físicas, siendo siempre posibles la resistencia y la revolución (p. 78), estas fuerzas precisan presentarse como mandato o deber (p. 79). La legitimación permite que, sobre la base de un mínimo de fuerza física (poder) eficaz, se consolide la relación de poder (el régimen de dominación) sin necesidad de un recurso permanente al ejercicio de la violencia, en virtud de una mixtura de consentimiento y fuerza potencial o amenaza de su uso (p. 79). Una fuerza irresistible, superior aun a la suma de todas las fuerzas parciales, capaz de imponer un orden estable, no existe en el mundo físicosocial y se requiere la voluntad de todos para crearla (p. 80). Lo que la fortalece es la adición del consentimiento. $\ll[\mathrm{L}]$ a fuerza verdaderamente eficaz es la fuerza legítima», que se justifica por ejercerse según un orden derivado de valores (justicia, bien común, voluntad de Dios, voluntad del pueblo...) (p. 81). La legitimación por los valores es siempre el resultado de un acuerdo entre juicios particulares definidos parcialmente a partir de intereses propios (p. 81).

Por tanto, el Derecho, a cuya esencia no pertenecen los fines distintos de la regulación de la fuerza, busca, sin embargo, siempre un fundamento trascendente. Esta pretensión de legitimidad que caracteriza la comunidad política estable- ce «la sutil divisoria entre el Estado y una banda de ladrones» (p. 83). La clave diferencial está en que «el titular de la fuerza pretenda ser tenido por un poder ajustado a una voluntad que le trascienda» (p. 84).

A partir de este punto, Requejo retoma su exposición sobre el Estado moderno. La comunidad política, que había buscado su fundamentación en el orden de la justicia, se convierte en el fundamento mismo de ésta. El Estado se basa en la voluntad en que consiste, que se constituye en virtud de un pacto hipotético, un acuerdo de todos que es a la vez una renuncia general a la autotutela. La fundamentación inmanente tiene la grave consecuencia de que todos los límites desaparecen, porque si los hubiera no habría soberano, que no puede estar sujeto ni siquiera al propio pacto (p. 88). Se acaba la guerra civil permanente si el poder es capaz de imponerse, pero aparece el problema de la libertad. Frente a ese poder irresistible no hay derechos, sólo cabe obtener tolerancia, gracia, benignidad... Ésta es la aporía del Estado con la que arranca el constitucionalismo, entendido como ideología de la limitación de la soberanía.

Lógicamente se insiste a continuación en la importancia de la Constitución normativa, en la línea de Ignacio de Otto. Tras sucesivos intentos de asegurar la libertad, «la 
experiencia acabó enseñando que el único camino factible era el teóricamente más sencillo [...] [E]l sujeto más adecuado para la titularidad de la soberanía [...] [es] un sujeto inexistente»: la nación o el pueblo, una abstracción, un sujeto ideal, una pura instancia de imputación, una cualidad del Estado y del ordenamiento, una entelequia (p. 93). Los individuos, en cuanto tales, son siempre sujetos sometidos al Estado, con los derechos y los deberes que el ordenamiento les asigne. El cuerpo electoral es un órgano del Estado (p. 95). El pueblo, o la nación, es el único soberano compatible con la libertad porque es un soberano incapaz.

Es evidente que esto no impide que las minorías obren en nombre de la huidiza soberanía popular. En realidad, lo que se sostiene es que el único soberano compatible con la libertad es un soberano normativo, una norma jurídica, una cualidad del Estado cifrada en la norma que lo constituye, en la Constitución (p. 95), y no cualquiera, sino una que cumpla ciertas condiciones, si bien se dice que estrictamente procedimentales, porque los derechos fundamentales, en el fondo, no son otra cosa que procedimiento. El único soberano compatible con la libertad es la Constitución racional-normativa. «[E]l fin de la libertad perseguido por el movimiento constitucionalista sólo era factible asumiendo los postulados del normativismo positivista» (p. 96), que configura la soberanía como factor de constitución del conjunto normativo en sistema autorreferente y completo (p. 96).

$\mathrm{Se}$ establece incluso una conexión lógica - más que discutible - entre la normativización de la Constitución y la relativización de todos los contenidos, salvo el procedimiento de formación de la voluntad colectiva mayoritaria reversible (p. 97). El argumento máximo a favor de la relativización de todo parece ser que estabiliza la comunidad política. Aunque, teóricamente, el pueblo - esa entelequia - conserva la facultad de disponer de la Constitución, que no ata al soberano, en la medida en que cualquier cambio es posible mediante la observancia de los procedimientos, se hace menos necesario el ejercicio revolucionario de la soberanía (poder constituyente). Con la garantía del respeto de la minoría, ésta, en cuanto capaz de llegar a ser mayoría, deja de ser facción y se vuelve inofensiva (p. 97). Se diría que hoy en España nuestra inestabilidad no lleva a pensar que no podemos seguir relativizando todo, sino que aún no bemos fluidifcado bastante el tránsito.

Deducir de la racionalidad del procedimiento la de los contenidos - el procedimiento somete a un orden de mandatos que es racio- 
nal, porque lo define una mayoría en permanente proceso de definición (p. 98), con lo que el Estado ya no se funda en una trascendencia inaccesible a la razón, ni en la pura eficacia de la fuerza organizada, sino en la razón, cuyo sueño, por cierto, engendra monstruosno cuenta a su favor con otra razón que la de la imposibilidad de la fundamentación absoluta del orden del deber ser. La limitación de lo bumanamente posible evidencia demasiadas veces la irracionalidad de las decisiones, cuya reversión también depende siempre de lo bumanamente posible.

Lo que todo esto significa, en realidad, es que la democracia desaparece o, por lo menos, se subordina al liberalismo. Lo que Requejo está defendiendo como la única democracia posible es que, por sobre todo posible cambio normativo, que puede ser cualquiera con tal de que se respete el procedimiento, subsista una arquitectura procedimental consistente en la posibilidad de decidir reversible y mayoritariamente con participación de todos los ciudadanos acerca de cualesquiera cuestiones de interés general.

En un libro muy bien construido, el autor, a la vez que avanza diacrónicamente, va profundizando en algunas cuestiones teóricas de máxima generalidad. Al comienzo del capítulo III, dedicado a los problemas de la concurrencia de los Estados soberanos, vuelve sobre la naturaleza o la función del Derecho, que, antes que sistema de interpretación de la realidad social, es el resultado de un determinado entendimiento de esa realidad (p. 125). Sobre la propia visión del mundo se construye una realidad ideal normativa, autónoma, suficiente, perfecta, un lenguaje propio, un sistema de conceptos y categorías. Desde ahí se vuelve sobre la realidad con las reglas sobre las condiciones para el ejercicio de la fuerza, que son las pautas de conducta para la imposición del deber ser (pp. 125-126).

Las sociedades no necesariamente se corresponden con perfecta simetría con las comunidades políticas que intentan regirlas, lo que constituye para Requejo el problema de la dimensión del Estado. El «paradigma hobbesiano» funcionó adecuadamente en las relaciones entre los Estados mientras cada soberano europeo sólo lo era sobre una sociedad concreta, en la que había podido imponerse efectivamente y en la que disponía de poder absoluto por sus propios medios (p. 127). La comunicación entre ordenamientos «podía reducirse a la delimitación de sus dominios, a la diplomacia y a la guerra» (p. 126). «Cada Estado constituía un universo propio en el que se contenía toda la realidad susceptible de ser ordenada en Derecho» (p. 127). 
Concurría con sus iguales en «un estado de naturaleza equivalente al abandonado por el individuo merced al pactum societatis» (p. 127). La realidad sometida a otros Estados sólo le era accesible mediante la guerra y el Derecho internacional era — según Requejo- apenas «incipiente» (p. 127). La primera norma era la que ordenaba obedecer al soberano y el Derecho positivo podía entenderse a partir de la categoría de la validez (pp. 128-129), cuya brillante teorización kelseniana (p. 161) obviamente pintaba en gris un mundo sobre el que ya habían caído las sombras de la noche.

Tras aludir al significado del reconocimiento mutuo de los Estados - que implica ya una claudicación de principio, pues el tratado internacional, norma compartida, ha de imputarse a una voluntad normativa superior (pp. 129-131) — y al ideal -inalcanzable en un horizonte previsible - de un soberano universal (p. 130), Requejo afronta el tema vertebral de todo el ensayo: la «quiebra del principio de simetría entre el Estado y la sociedad jurídicamente organizada»; fenómeno, a su juicio, «en progresión desde el último tercio del siglo $\mathrm{XX} \gg$. La noción de dimensión evoca la imagen de una sociedad que vive y se expande más allá de las fronteras a las que el poder del Estado puede alcanzar. Es obvio que la percepción de que los Estados naciona- les europeos están agotados no es nada nuevo. Podríamos traer aquí a colación muchos textos. «El Estado moderno - que es el eje de la civilización moderna- se ve hoy acosado por todas partes. Está superado políticamente por la constelación de hegemonías, articuladas por superestados; minado moralmente por la crisis de la Nación, que constituía su alma, el verdadero espíritu objetivo; desmantelado en su función esencial, que es la seguridad jurídica y física de la comunidad, y [...] desbordado por una economía sin fronteras, por un mercado universal que arruina la potencialidad política de la soberanía nacional. La gran mutación histórica por la que atravesamos se organiza en torno al fenómeno de las gigantescas corporaciones multinacionales» (Jesús Fueyo).

Requejo se refiere especialmente, con Thomas Piketty, al fenómeno de las sociedades aestatales, «estructuras de relación social y de dominio que [...] participando selectivamente del orden establecido por una pluralidad de Estados, se desenvuelven con relativa independencia frente a todos ellos [...] encuentran en la concurrencia de ordenamientos las condiciones ideales para [...] eludir [...] las responsabilidades y los deberes» (p. 132). Pero, con ser de enorme importancia, no se trata solamente de esto. Los Estados más fuertes pueden hacer respetar la posición 
que les corresponde en el equilibro «alcanzado [...] tras la última gran recomposición de la distribución de la fuerza realizada en el siglo XX» (p. 133), pero los peor dotados dependen de que su supervivencia sea de interés para la estrategia de quienes se arriesgarían a comprometer el statu quo si un reequilibrio pudiera favorecerlos (p. 134). Para Estados como España, que han perdido esa simetría recuperada altivamente en el siglo $\mathrm{Xx}$, parece que la situación no sería aún desesperada, pero sí tan comprometida como para haber abocado a un compromiso que puede llevar a que, prácticamente, la soberanía acabe por reducirse a sujeción (p. 145). Los Estados no hegemónicos europeos, con el protagonismo de Francia y Alemania, han desencadenado a la fuerza una importante mutación cualitativa del Derecho internacional, vinculándose en tal forma por medio de una tupida red de tratados que, si bien aún falta en general, por lo menos formalmente, «la seguridad que sólo puede dispensar la fuerza de un tercero incontestable», la confianza mutua y el miedo aseguran poderosamente frente a la infracción. El soberano admite que hay otras fuentes del Derecho. En este punto, como es lógico, reitera Requejo su concepción de la técnica de la aplicabilidad, categoría en que formalmente «se quintaesencia la sustancia de la sobera- nía» (p. 139), es decir, a la que ésta ha quedado reducida. Soberano no es «quien decide sobre la validez de las normas del sistema, sino quien determina qué normas, con independencia de la causa de su validez, se integran efectivamente en el proceso de administración de la violencia» (p. 140). La categoría de la aplicabilidad, sobre todo hacia fuera del Estado, no sólo articula teóricamente el sistema perfeccionando su autorreferencialidad, sino que, sobre todo, representa un nuevo avance en la relativización del poder (p. 141) y un factor de pacificación con la sujeción al Derecho de las relaciones internacionales (p. 148). El carácter exquisitamente formal de la consideración de que esto no afecta a la sustancia del poder soberano (p. 145), puesto que la norma internacional incompatible no invalida la Constitución, al ser el régimen de la aplicabilidad preferente de la norma externa algo asumido en su momento por ésta (p. 156), se pone limpiamente de relieve cuando se reconoce que la reversibilidad de los compromisos no está ya en la sola mano de cada soberano y que en la integración, más o menos desfigurada, de su Derecho el juez europeo puede hacer valer las exigencias de su propio sistema normativo (p. 154). Se hace inevitable recordar - entre las reflexiones de Requejo sobre las normas preconstitucio- 
nales, la distinción entre sistema y ordenamiento, y la definición de la Constitución como norma sobre la aplicabilidad de las normas- el arranque de la introducción a Sistemas normativos: el Estado nacional parece haber querido corroborar sus bondades arbitrando los medios para su disolución. En esta marcha hacia la liquidación hay sin duda también una línea de no retorno que, por cierto, los ingleses no han querido pisar.

El diagnóstico de la impotencia ordenadora de nuestros Estados se profundiza en el capítulo IV, particularmente desde la perspectiva de su faceta democrática. El éxito del constitucionalismo, de que se da razón en el capítulo III, se ha resuelto en forma harto paradóji$\mathrm{ca}$, lo que nuevamente nos devuelve a la ironía como forma del espíritu objetivo en caída libre.

Para empezar, deberíamos ser conscientes de su excepcionalidad. El mundo (no europeo) está lleno de Estados cuasiabsolutos y de territorios sin estatalidad eficaz, en los que - se reconoce- hasta es harto dudoso que la democracia -el sufragio universal entre partidos políticos - tenga funcionalidad positiva alguna. Su éxito, además, «será siempre contingente», al implicar un equilibrio precario en el que la fuerza conserva su inercia o puede reaparecer (p. 167). Pero lo más llamativo es que Requejo acepta que el constitucionalismo, con su obsesión por el límite, ha ido demasiado lejos, hasta contribuir a la erosión de la soberanía (p. 168). En este punto la autocrítica, claro está que no más allá de la relativización del relativismo, es punzante, masoquista. En la vertiente externa, poner en peligro la fortaleza del Estado es suicida y, sin embargo, nuestra manera de pensar o nuestra experiencia histórica propicia —según Requejo- una creencia peligrosa en que se progresa hacia la convivencia pacífica (p. 169). La realidad internacional está aún demasiado cerca del estado de naturaleza. Con los Estados más o menos constitucionales o constitucionalizados cabe esperar una relación relativamente civilizada, pero hay muchos otros basados en ideologías incompatibles y voluntades agresivas ante los que sólo merece respeto el capaz de defenderse. El ensueño pacifista es impracticable porque no es sinceramente compartido (p. 170). Hay que convencerse de que la violencia no es suprimible. En el Estado constitucional no hay soberano, pero el Estado no puede dejar de serlo, no puede aparecer al exterior como una criatura desarmada (p. 170). En este terreno sólo la centralización y la autonomía de las decisiones garantizan el respeto y difícilmente puede haber más límites que unas pautas de principio y 
la responsabilidad por la gestión (p. 171). La fortaleza exterior del Estado exige que la dirección de la acción exterior pueda ejercerse eficazmente, lo que obliga a sacrificar el postulado de la acción concertada de Gobierno y Parlamento. La deliberación parlamentaria y la revisión judicial se compadecen mal con la resolución expeditiva.

Pero el equilibrio entre libertad y seguridad, límites y eficacia, es también difícil en la esfera interna. La crítica se dirige al Estado social, Estado de bienestar o Estado providencia, pero en un sentido que no es el de la crítica liberal corriente, que apuntaría, sobre todo, a que, si se impone al Estado una misión de realización positiva de la libertad, o se relajarán los límites o peligrará la autoridad (p. 172), sino, sobre todo, a la sustantivación del ordenamiento desde la misma Constitución, contra el sano principio de la relatividad de las esencias, con el grave resultado de peligrar seriamente la capacidad estatal de estabilización del orden social (p. 173). Por la década de los ochenta lo que se veía en la Constitución a lo largo de sus proclamaciones de derechos y principios económicos y sociales era más bien que con ella se podía llegar a cualquier parte, como dijo en alguna ocasión Enrique Tierno, es decir, un cierta - virtuosa o arriesgada - ambigüedad entre modelos de sociedad. No es ésta la preocupación de Requejo. En realidad, esa ambigüedad — a mi juicio, muy difícil de negar- fue resuelta, o más bien puesta en suspenso, por el Zusammenbruch soviético, así como el centrifugado autonómico de las nacionalidades fue contenido, temporalmente y más bien mal, por subordinación normativa. Desde esta perspectiva es comprensible que sólo se aprecie una sustantivación del ordenamiento, que iría contra la esencial reversibilidad de las decisiones. La sustantivación material del ordenamiento impulsa la judicialización, y aun el activismo, y dificulta la configuración de voluntades alternativas (p. 174). La instauración de límites constitucionales sustantivos siempre complica el sistema, porque, aun siendo procesales, es decir, removibles mediante reforma constitucional, en la práctica no hay posibilidad de negociar una reforma y se vuelven inconmovibles (p. 175), pero la verdadera complicación no proviene de la existencia de tales límites, sino de haberse vuelto límites positivos (p. 175). Ya no basta con la constitucionalización de unos derechos y su irradiación por todo el ordenamiento, sino que se postula su realización efectiva, su aseguramiento frente a la decepción, lo que obviamente no es posible (p. 176). Se cree que el deber ser puede siempre realizarse totalmente y se configura una suerte de realidad idealizada 
(p. 176). Todo lo imaginable puede hacerse real con ayuda de las normas (p. 177). Se propicia el curso de la fantasía y el distanciamiento de la realidad (p. 174). Dejando aparte que lo imaginable venga resultando demasiadas veces más bien monstruoso, precisamente en el sentido de Goya, lo cierto es que se crean expectativas que fatalmente serán defraudadas con grave daño para la autoridad del Derecho (p. 177). La tendencia futurista del alma de Occidente lleva en sí el principio de la decepción.

Aquí se halla el núcleo de la argumentación de nuestro autor $-\mathrm{y}$ acaso el nudo de nuestra situación-, en el diagnóstico de una grave dificultad para el cambio político. La impotencia ordenadora y la expansión de la mentalidad de idealización fantasiosa de la garantía estatal de la realización individual - que refleja simplemente, a mi juicio, que el hombre de hoy ha perdido el sentido de la realidad - han llevado — piensa Requejo- a una articulación del debate político en términos de cumplimiento y aplicación de programas normativizados al máximo nivel. Las soluciones, especialmente las que contrarían las pulsiones electorales, tienen que presentarse con la máxima inevitabilidad de lo jurídicamente obligatorio. No deja de ser llamativo, chocante, paradójico, que, cuando se proclama como principio y sistema la reversibilidad de todas las decisiones, la posibilidad de todos los cambios y, en definitiva, la absoluta libertad de los vivos para zafarse de toda responsabilidad histórica, se detecte con preocupación una oclusión del cambio, una notabilísima dificultad práctica para la innovación y la reforma (de unas sociedades que no van a sobrevivir si no se reforman honda y radicalmente).

En este orden de consideraciones, Requejo no ahorra reproches a la radicalización del principio democrático, que hace muy difícil la aplicación efectiva de las normas y de la misma fuerza legítima, incluso ahora, por ejemplo, que se ha hecho mensaje oficial que una legalidad que se puede cambiar postula ineludiblemente su cumplimiento. Democracia y Estado son esencialmente incompatibles, porque la democracia es la sublimación de la voluntad de la mayoría y el Estado es orden (p. 177). La única democracia posible es la que configura la voluntad general a través de procedimientos en que, con participación de todos, se garantice la formación y expresión de la voluntad circunstancialmente mayoritaria con seguridad de que la minoría del presente pueda llegar a ser mayoría en el futuro (p. 177). Esta democracia ciertamente necesita del Estado, no puede existir sin un Estado que establezca los procedimientos y garantice su respeto (p. 177). Por 
otra parte, sólo el Estado democrático hace verdadera economía en su esfuerzo de dominación, puesto que el consentimiento genera legitimación que contribuye decisivamente a la estabilidad (p. 178), lo que es otra manera de decir que la democracia, una vez recuperada para la cultura política occidental por la constitución norteamericana, se ha convertido, tras la victoria antifascista de 1945, en la única forma legítima de ordenación de la convivencia (p. 179) ${ }^{2}$.

Por tanto, se requiere un equilibrio. La voluntad de la mayoría no puede reducirse a las cuestiones menores, pero tampoco todos los niveles de la regulación pueden dejarse al albur del capricho mayoritario (p. 178). Hoy, la composición de estos principios no es equilibrada y la democracia se está convirtiendo en demagogia (p. 178). Aunque Requejo se cuida de una retórica de truenos apocalípticos, sus frías advertencias no son menos graves.

La última parte de este capítulo IV profundiza aún más en el análisis de la radicalización del principio democrático, que debe tener una función puramente adjetiva (p. 180). La lógica democrática no puede pretender operar en todas las dimensiones de la vida. Esto es gravemente disfuncional para la eficacia y la libertad (p. 180). En los niveles estatales normativos en que predomina la aplicación sobre la creación no cabe más que la discrepancia jurídica (p. 180). En los dominios de la capacidad y el mérito, la educación, la ciencia, la sanidad y la milicia son actividades que dependen del conocimiento, no de la opinión, y que han de realizarse adecuadamente en interés de la misma libertad (p. 181).

Pues bien, ni siquiera los Estados democráticos que ponderan mejor ambos principios se libran hoy de una cierta perversión de la democracia en la formación de la voluntad general y en el control del poder. La democracia representativa puede conjurar los peligros de dominación minoritaria, pero no se libra del grave riesgo de la tiranía de

${ }^{2}$ La democracia, obviamente, admite variantes. El mismo Requejo parece reconocer que la parlamentaria y de partidos pudiera no ser la única variante legítima, bajo la condición de que la voluntad actual de la comunidad determine siempre la normatividad y pueda cambiarla, con exclusión de que una voluntad circunstancial pueda erigirse en soberano real y concreto (p. 179). Muy claramente, una cosa es que la democracia deba ser necesariamente de partidos y otra cosa distinta, que no se relativice todo, y aun que una cierta estatalidad domine sobre la subordinación de las decisiones a la voluntad de la mayoría, es decir, coordinar el principio democrático con la vinculación existencial del Estado al bien común de la sociedad y al destino histórico de la comunidad. La democracia es un procedimiento normativo en que prevalece la participación de todos bajo una regla de mayoría, pero la democracia es también - y ahí radica el supuesto civilizatorio — la forma de organización social que pone todo al alcance de todos (Boorstin). 
la opinión (p. 182), cuya racionalidad depende de la ilustración y de la responsabilidad de los electores (p. 182). En este punto justamente el Estado se revela $-\mathrm{y}$ se rebelacomo eticidad. La democracia parlamentaria está funcionando hoy bajo la presión permanente de una opinión pública irracional. La acción de gobierno debe ser programada a partir de principios bien definidos y debe ejecutarse atendiendo al interés general y no sólo al de los que han votado a favor (p. 183). Aun la opinión más ilustrada es demasiado parcial, ayuda a percibir las líneas de tendencia, pero no necesariamente identifica lo más conveniente al interés general ni lo más adecuado en la gestión de lo inmediato, mucho menos donde no hay verdadera opinión pública socialmente institucionalizada (p. 183). Muy claramente la estatalidad ha de prevalecer sobre la opinión, pero ¿cómo?, si la continuidad de la acción de gobierno depende de un voto prefigurado en ella y la acción partidaria está subordinada a una falsa opinión públi$\mathrm{ca}$, en condiciones que las técnicas demoscópicas y la comunicación digital han empeorado por el predominio de la imagen, la impresión del instante, dentro de un proceso electoral continuo que impide una verdadera acción institucional (p. 184), lo que se agrava cuando por la descentralización política hay elecciones constantemente. De esta manera se hace muy difícil una acción eficaz de gobierno que exija medidas impopulares y todo se queda en una gestión de corto plazo (p. 185), en una agitación por la supervivencia burocrática de los partidos.

Frente a esa opinión sólo se sabe hallar argumentos de inevitabilidad. Por eso, el debate se vuelve «jurídico» y se judicializa. Hay un recurso continuo en todos los niveles a los órganos judiciales, a los que se trasladan problemas fundamentales de definición política (p. 190). Pero hasta esto es secundario. Sobre todo, hay una mentalidad de derechos y libertades que se traduce en pretensiones que buscan satisfacción y que vuelven electoralista toda política. Se siente imposible una acción de corrección, de verdadera renovación, de vuelta a los principios. Pesa en esa mentalidad la propia Constitución en cuanto catálogo de derechos positivos. Todo se conjura en beneficio de una formidable ineficacia (p. 191).

La contradicción entre la idea liberal, de hacer ineficaz el poder en interés de la libertad, y la idea del Estado providencia o Estado de bienestar, de la realización de las condiciones materiales para la satisfacción del más amplio catálogo de derechos, podría acaso alcanzar un equilibrio, pero esto exige una dimensión adecuada del Estado y una racionalización del principio democrático (p. 192) que a Requejo 
le parece que llegó a iniciarse pero que hoy habría fracasado.

Desde 1917 pugnaban por la herencia de los ideales ilustrados la libertad formal y la libertad material (libertad para todos). La solución comunista radical quería la libertad igual para todos mediante la supresión de la propiedad, que es la manera de superar la desigualdad que imponen las condiciones materiales. En un mundo de notable desigualdad, esto cautivó a las masas, aunque el igualitarismo acababa con la libertad (p. 193). Para enfrentarse al comunismo soviético, el demoliberalismo tuvo que aceptar una cierta implicación del Estado en la creación de condiciones que incrementaran y masificaran la libertad real, aunque sin una nivelación total en la desposesión (p. 194), lo que en el plano de los principios era sin duda contrario al maximalismo liberal ${ }^{3}$.
El capítulo V concluye el razonamiento de todo el libro con la tesis hasta la que Requejo quería conducir a sus lectores. «La edad de los Estados nacionales europeos llegó a su fin con la segunda Guerra de los Treinta Años (1914-1945) [...] [E]1 modelo de comunidad política establecido con la Paz de Westfalia [...] sólo es ahora viable en comunidades que trascienden los límites del viejo Estado nacional». Han sido superadas sus dimensiones, pero no su concepto, que —según Requejoes válido ahora para las superpotencias del siglo XXI (p. 219). El Estado soberano es una creación admirable del ingenio humano, capaz de redimensionarse en cada momento histórico según sus exigencias materiales.

La percepción de que los Estados nacionales europeos están agotados no es nada nuevo, pero sí es muy interesante (aunque tampoco

3 El demoliberalismo y la democracia popular comunista se describen como dos variantes del pensamiento de la Ilustración, y el nacionalsocialismo o el fascismo es absolutamente otra cosa, lo totalitario (pp. 193-194). Esto es hasta cierto punto verdad, pero una verdad que no es precisamente amable, porque el derrumbamiento del marxismo real anula toda la línea de evolución de mentalidad e ideología alumbrada por la magna aurora de la razón, por lo que con razón se ha dicho que lo que ha quedado después no es otra cosa que un inmenso cráter del espíritu. La verdad es que, como en virtud de la propaganda antifascista sólo quedó en pie la democracia, se encontraron ideológicamente inermes en un contexto de ruina y retrocedieron al liberalismo del siglo XIX, pero naturalmente tuvieron que hacer frente al peligro revolucionario comunista, que se vio entonces en su tremenda significación, y lo hicieron, como no podía ser de otra manera, en el plano de la política real, no en el de las vagas ideas abstractas, en el que toda la herencia de los ideales ilustrados estaba en poder de Stalin. Lo hicieron por todos los medios de la razón de Estado, pero, sobre todo, mediante inversiones interesadas para el desarrollo económico y la creación del gran escaparate estratégico de la sociedad de consumo. Así pudieron acabar contraponiendo el mundo que sólo era capaz de realizar cierta igualdad a costa de la miseria y la opresión, al mundo en que todos podían más o menos acceder a un consumo en constante expansión. 
absolutamente original) la explicación que Requejo ofrece sobre la génesis y desenvolvimiento de las instituciones comunitarias europeas. Los propios Estados soberanos, en trance de disolución por incapacidad reguladora, han hallado un remedio para sus males. La Unión viene a ser un soberano funcional, suma de las voluntades de los Gobiernos parlamentarios nacionales, capaces así de generar una normativa prevalente que, bajo la técnica, tan agudamente teorizada por el mismo Requejo, de la aplicabilidad, elude los límites y controles normativos y políticos internos y logra imponer un orden económico en el que, como muy visiblemente sugiere el mismo Requejo, predominan los intereses financieros y de las grandes empresas trasnacionales, con el contrapeso de la tutela del consumidor. Es ahora cuando se cumple la utopía de la economía como derecho natural de la sociedad humana, y naturalmente se cumple antiutópicamente, como se cumplen todas las utopías.

Requejo interpreta toda la evolución de las instituciones europeas, por lo menos desde la creación del Parlamento, como el resultado de un equívoco sobre su naturaleza (pp. 223-225). La nueva estructura no pretendía ser un Estado y le faltaban casi todos sus atributos, por lo que, desde el punto de vista constitucional clásico, «no cabía imaginar mayor [...] desorden». Se ideó como remedio «organizar como un Estado lo que no era tal» (p. 222). La parlamentarización es falsa, pues en las cuestiones sensibles fracasa. Esta esquizofrenia hace imposible identificar el sujeto del control político, fomenta el «descreimiento democrático» (p. 225), desvirtúa los derechos fundamentales (p. 226), confunde al ciudadano con el consumidor (p. 227). La Carta de Derechos Fundamentales extrema la contradicción interna, porque una comunidad de derechos postula un poder con plenas competencias (p. 230). La inflación de enunciados de derechos es fuente de confusión y puede ser contraproducente aun para la pretendida mejor protección de la libertad individual (p. 232) ${ }^{4}$.

${ }^{4}$ Es interesante contrastar las opiniones de Requejo con el también muy reciente libro de S. Muñoz Machado, Vieja y nueva Constitución, Barcelona, Crítica, 2016, especialmente sus capítulos IX y X, que se inscriben muy claramente - y como es obvio esto tampoco se dice aquí en sentido peyorativo- en la confusión multinivel. Cfr., últimamente, R. AliBRANDI, «Extra ordinem. Breve storia del costituzionalismo multilivello tra volontà d'integrazione, dialettica delle differenze, globalizzazione e trasformazioni dello stato», Foro, vol. 19, núm. 2 (2016), pp. 57-95. Según Muñoz Machado, tal vez no volverá a haber en Europa un proceso constituyente como los de los siglos XIX y xx. El tipo de proceso constituyente no importa mucho, siempre que el resultado sea una verdadera Constitución europea (p. 209), como demostraría 


\section{El maximalismo constitucionalis- el límite- ha provocado la impo-} ta - los excesos de la obsesión por tencia del soberano nacional y, de

el ejemplo de los Estados Unidos de América (pp. 209-211). Los Tratados equivalen ya, en «muchos rasgos jurídicos», a una Constitución: sus nomas son jerárquicamente superiores; un orden jurisdiccional asegura el respeto a la legalidad de la Unión; se reconocen derechos y libertades fundamentales; el reparto de competencias se aproxima cada vez más a los modelos federales; la reforma de los tratados presenta una rigidez asimilable; muchas políticas que han caracterizado al poder soberano durante siglos se forman ahora en las instituciones europeas. No obstante, el derecho de separación reconocido en los tratados puede aún comprometer la estabilidad y la territorialidad europeas (Muñoz Machado, p. 211). Dejando ahora al margen que algunos de estos rasgos no pueden aceptarse, por lo menos en la forma en que se enuncian, la cuestión central se plantea en los términos en que la pone en suerte Requejo. La soberanía de las instituciones europeas es una soberanía funcional, con la que actúan sobre las sociedades nacionales los gobiernos de los Estados miembros, sin la necesaria correspondencia ente gobernantes y gobernados que exigiría una verdadera estatalidad europea: «[E]l ciudadano de un Estado miembro no puede decidir sobre la identidad ni sobre la conducta de los Gobiernos de los demás Estados en tanto que sujetos de la acción comunitaria, y sólo con dificultades está en situación de exigir responsabilidad a su propio Gobierno por su proceder en las instancias europeas» (Requejo, pp. 201-202). Los que comparten el ejercicio de la soberanía son los gobiernos de los Estados, que ejercen así un cierto control materialmente reducido a las relaciones de la economía y realmente supeditado a los vientos del mercado pretendidamente global. Muñoz Machado reconoce que las instituciones tienen tantas debilidades en su funcionamiento ordinario que las políticas difícilmente pueden acometerse y ejecutarse con eficacia (p. 211) y que la cuestión del poder constituyente y de la titularidad de la soberanía sigue sin resolverse (p. 216). La explicación que propone consiste en «superar la concepción de la soberanía como poder originario e indivisible [...] y [...] revisar la idea de que la Constitución sea una decisión dirigida a establecer en un solo acto, y de una sola vez, un nuevo orden [...] La Constitución europea es de [...] naturaleza evolutiva [...] Y además [...] la soberanía de la Unión es la suma de las soberanías renunciadas y transferidas por los Estados [...] Han creado la norma fundamental de forma progresiva [...] en diversos textos [...] [y con] decisiones soberanas que proceden de diferentes estados». Los Estados «no sólo aceptan [...] transferir [...] poderes soberanos, sino también renunciar a la propia soberanía». Por tanto, lo que existe ya, ahora, es una «organización federalizante» y «un curioso retorno a la compartición de la soberanía». Concurren «un poder en formación y otro establecido» (pp. 218-219). Con ello es obvio que se viene a dar la razón a Requejo cuando habla del nuevo monstruo, Erisictón, que trata de sobrevivir alimentándose de sí mismo. Toda la legislación nacional «queda en nada ante la más modesta disposición comunitaria por obra y gracia del principio de primacía» (Requejo, p. 197), pero no se puede decir que un soberano europeo ya haya aparecido, porque el monopolio de la fuerza legítima lo siguen teniendo los Estados (p. 199). El repaso de las vicisitudes nacionales de Maastricht y Lisboa (Muñoz Machado, pp. 218-242) en nada desmiente el análisis de Requejo. Necesitamos un soberano, no una confusión de poderes. Es bastante claro que, yendo más allá de la noción estrictamente jurídica de la soberanía, en lo que Muñoz Machado no considera la tesis de Requejo sobre la aplicabilidad, lo que se evidencia es que políticamente nuestros Estados son aún soberanos, pero unos más que otros. No sólo Francia ha defendido unas inciertas condiciones esenciales de la soberanía nacional, sino que Alemania, cuyo peso demográfico y económico condiciona todo el proceso europeo, aunque, en efecto, no tiene hoy otro horizonte histórico que el de núcleo masivo de Europa, se reserva la última palabra. Todo esto contrasta con la forma en que Maastricht y Lisboa fueron manejados por nuestro Consejo de Estado y nuestro Tribunal Constitucional (Muñoz Machado, p. 235). 
rebote, su recurso a esa argucia de la erección de un soberano funcional que, sorteando los límites, se impone - en los terrenos de la economía y en el sentido del interés del mundo de los negocios y de las finanzas- a la sociedad democrática. Insistir en poner límites ahora al ejercicio de las competencias de ese soberano funcional en modo alguno corregiría el problema básico, que es el de la ingobernabilidad, el del desorden, el de la debilidad del poder que debería actuar en el orden de los principios, de la educación del hombre europeo, del rescate del espíritu, de la cultura y de la naturaleza.

Más democracia en las instituciones europeas, mientras no se constituya el soberano europeo, sólo puede agravar los problemas 5 . La Unión ya es democrática en el único sentido en que puede serlo (mientras no sea $\mathrm{el}$ Estado europeo): su voluntad normativa la constituyen sus miembros, que son los Estados y no los ciudadanos. Una unión o comunidad de Estados soberanos no puede conceder participación democrática en sus decisiones más que a los Estados que la componen. Otra cosa diferente es la constitución de un pueblo en el que se comprendieran los ciudadanos de todos los Estados de Europa. Si este pueblo, en cuanto cuerpo electoral, designara un Parlamento europeo con auténtico poder normativo superior, estaríamos ya en presencia del Estado federal europeo. La democracia ciudadana europea es incompatible con unos Estados nacionales soberanos. Tan pronto como aquélla aparezca, la soberanía de éstos se acaba. Es lógico pensar que, por lo menos en principio, como no sea a la fuerza, los Estados que han creado la Unión o la componen no van a permitir esa transformación sustancial. Por eso no parece que el surgimiento del Estado europeo a partir de la Unión pueda ser el resultado de un desenvolvimiento natural de ésta. Jesús Fueyo decía que Europa caminaba hacia su unión, pero destruyendo todos los días sus posibilidades de unidad. Los Estados han incoado el proceso, pero sin intención de liquidarse. No cabe esperar que ellos mismos vayan a transformar lo que ha sido «unificación selectiva y controlada» para «renunciar al monopolio de la violencia legítima». La integración europea «es un fenómeno radicalmente contrario al espíritu del constitucionalismo» (p. 218).

Sin embargo, la recomposición de los Estados nacionales ya no es posible, a juicio de Requejo. El

5 Sin embargo, la crítica general de las instituciones europeas no impide verlas como la mejor garantía posible de la libertad para los ciudadanos de los Estados miembros poco democráticos (p. 215). Es decir, en todo caso, las instituciones son la garantía de que los Estados europeos no van a abjurar del «dogmatismo democrático». 
Estado nacional ya no tiene dimensión, ya no tiene la población y los recursos que harían falta. El escenario de la soberanía ya no puede definirse por las fronteras de las naciones, porque la sociedad ya no contiene su movilidad, su dinamismo, en esos confines y porque los poderes sociales y económicos los superan y desbordan. «El Estado nacional europeo ya no es el escenario del poder que importa» (p. 215).

En conclusión, me parece que se puede decir que Requejo es en el fondo bastante pesimista. Se hace difícil pensar otra cosa cuando ha colocado sus reflexiones bajo la alucinante y alucinada mirada de Goya al sueño de la razón. Defiende la estatalidad moderna y la ve sólo posible en la dimensión continental, pero es consciente de las duras resistencias que cabe esperar. Además, me parece visible que desconfía de la evolución de Rusia, que conserva su vocación de nueva Roma. Sobre todo, denuncia las graves deficiencias de nuestras democracias en cuanto a opinión pública y educación. Piensa que la democracia ha de tener límites y que el equilibrio de estatalidad y democracia está hoy desestabilizado.

El núcleo de la argumentación se halla en el diagnóstico de una cierta y grave dificultad para el cambio político. La impotencia ordenadora y la expansión de la mentalidad de idealización fan- tasiosa de la garantía estatal de la realización individual —que refleja simplemente, a mi juicio, que el hombre de hoy ha perdido el sentido de la realidad - han llevado a la articulación del debate político en términos de cumplimiento de programas normativizados (en los que está alienada la masa votante). Las soluciones, especialmente las que contrarían las pulsiones electorales, tienen que presentarse con la máxima inevitabilidad. No deja de ser llamativo, chocante, paradójico, que cuando se proclama como principio y sistema la reversibilidad de todas las decisiones y la posibilidad de todas las novedades se detecte con preocupación una oclusión del cambio, una notabilísima dificultad práctica para la innovación y la reforma (en unas sociedades que no van a sobrevivir si no se reforman honda y radicalmente). Creo que este problema debe enfocarse adecuadamente. En rigor, el cambio social se ha hecho continuo. Esto se aprecia especialmente en la fractura generacional que muestran nuestras sociedades, en las que todo muda de cara una o dos veces cada diez años. Estamos inmersos en un cambio permanente cuyo sentido no se percibe, no controlamos y se nos escapa. Es un cambio que implica demasiadas veces el comienzo de lo mismo, el eterno retorno de las decepciones y de las frustraciones. La dificultad para el cambio a la 
que acertadamente apunta Requejo es, según entiendo, la que se refiere a una acción ordenada de reforma social y cultural que nos devuelva el dominio de nuestro destino. La reversibilidad de todo ha motivado la irreversibilidad del caos, la imposibilidad de generar orden que nos pone en la situación límite en que sólo un dios puede salvarnos, pero desconocemos qué dios.

Es difícil contradecir el diagnóstico, al que Requejo se adhiere - Schmitt planea por sobre toda la obra sin ser mentado una sola vez-, acerca de la expiración del tiempo de la estatalidad nacional europea (p. 255). Pero, cy el alma del Estado, que es su espíritu objetivo? He citado un par de veces a un viejo maestro español que no debiera haber caído en el olvido, porque me interesa llamar la atención - para acabar con la lectura de este valioso libro- sobre un pensamiento en que solía insistir como europeísta que también era: la gran política europea, la que enseña a volar a la búsqueda de los porvenires lejanos, tiene que empezar por la pedagogía del hombre europeo, que es casi como decir por la creación del hombre europeo. No puede haber Estado europeo sin Nación europea. Pero, ¿de dónde vamos a sacar los materiales si son las viejas naciones europeas las que están erosionadas moralmente hasta el extremo que Requejo describe en su página 249? Por lo demás, hay razones para temer que el mismo realismo que Requejo aplica para medir las posibilidades de nuestros viejos soberanos, impone darse cuenta de que es Europa la que ya no tiene dimensión. Si esto es así, el vacío ideológico, el poder de los mercados y la geopolítica de los superestados nos colocan ante un porvenir muy oscuro del que la separación británica parece ofrecer el más serio indicio.

Justo GÓmez Díez Departamento de Derecho Civil. UCM

AAVV, Condiciones de empleo y relaciones de yrabajo en el Derecho de la Unión Europea. Un estudio de jurisprudencia del Tribunal de Justicia, dirigido por J. García MurCia, Cizur Menor, Aranzadi, 2017, 991 pp.

Tiene el lector ante sí una obra colectiva fruto del esfuerzo de diecinueve profesores especialistas en materia laboral y de seguridad social, dirigido y coordinado por el profesor Joaquín García Murcia, donde se abordan diferentes cuestiones relativas a las condiciones de empleo y las relaciones de trabajo a la luz de disposiciones norma- 